\title{
PERANCANGAN BUKU ILUSTRASI POP UP DENGAN TEMA PERILAKU SOPAN SANTUN SISWA DALAM KEHIDUPAN SEHARI-HARI UNTUK TK AL-FAUZI MEDAN
}

\author{
Salam Irianto Nadeak ${ }^{1}$, Rika Aulia Hasibuan ${ }^{2}$ \\ Politeknik Negeri Media Kreatif \\ salamirianto66@gmail.com
}

\begin{abstract}
Sopan santun merupakan salah satu materi penting dalam kehidupan yang harus dikenalkan sejak dini. Dengan menerapkan sopan santun seperti menyapa teman, meminta maaf, berterimakasih, menghargai orang yang lebih tua dan sebagainya, maka akan menjadikan seorang anak yang disenangi banyak orang. Namun, sebagian guru memiliki kesulitan untuk mengenalkan sopan santun kepada anak yang Sulit konsentrasi. Oleh karna itu, tujuan penelitian ini adalah untuk merancang sebuah media pembelajaran berupa Buku Ilustrasi Pop Up dengan Tema Sopan Santun Siswa dalam Kehidupan Sehari- yang ditujukan untuk siswa TK Al-Fauzi Medan.

Perancangan gambar yang bertujuan menyampaikan informasi atau pesan (berkomunikasi). Jadi, desain grafis adalah merancang komunikasi dengan gambar. Tujuannya, agar pesan yang hendak disampaikan media tersebut diterima dan sampai kepada pembaca. Dalam perancangan Buku Ilustrasi pop up metode pengumpulan data yang dilakukan adalah dengan cara studi pustaka, observasi, dan wawancara. Adapun informan penulis ialah kepala sekolah dan guru TK AL-Fauzi Medan. Hasil dari Buku Ilustrasi ini adalah berupa sebuah buku yang didesain dengan konsep Pop Up, ilustrasi yang lucu, dan warna warna yang cerah untuk menarik minat belajar pada siswa. Pada sampul diberikan salah satu ilustrasi sopan santun berupa berpamitan dengan orang tua. Melalui perancangan buku ilustrasi ini, para siswa diharapkan dapat mengenal sopan santun.
\end{abstract}

Kata kunci : perancangan, buku ilustrasi, pop up, sopan santun

\section{PENDAHULUAN}

Anak yang sehat, cerdas, sekaligus santun dan berperilaku baik adalah idaman semua orang. Tapi pada kenyataannya, untuk mendidik dan membentuk anak untuk berkarakter positif bukanlah hal yang mudah. Diperlukan kesabaran dan ketelatenan serta kemauan untuk terus belajar dan memperbaiki diri dalam membimbing dan yang paling penting menjadi teladan bagi anak.

Berdasarkan hasil riset yang dilakukan pada guru di TK AlFauzi Medan, ada yang mendapati anak-anak yang tidak suka belajar dan tidak mendengarkan perkataan guru. Sehingga ketika guru menjelaskan anak-anak cenderung mudah bosan dan megalihkan perhatiannya dengan bermain hal lain. Padahal salah satu yang menjadi materi inti di TK Al-Fauzi ialah sopan santun.

Di TK Al-Fauzi sendiri proses pembelajaran mengenai akhlak dan sopan santun dimulai dengan guru memberikan teori yaitu membacakan buku yang berisikan hal baik dan buruk, kemudian 
memberikan contoh seperti membuang sampah pada tempatnya, lalu nantinya anakanak akan dibimbing secara langsung untuk melakukan dengan cara diingatkan dan ditegur. Untuk menangani anak-anak yang sulit memerhatikan guru, biasanya guru akan memberikan peringatan seperti, jika ia tidak mendengarkan dan tidak dapat menjawab soal yang diberikan maka anak tersebut tidak boleh pulang. Meski ancaman ini tidak dilakuan sebenarnya namun hal ini dapat memancing anak untuk kembali fokus. Selain itu, ada pula beberapa guru yang mendongengkan kisah-kisah yang menarik untuk menyelingi materi di kelas.

Berdasarkan masalah yang telah dikemukakan, maka penulis ingin membantu para guru yang ada di TK Al-Fauzi dengan memberikan pengalaman proses belajar mengajar yang lebih menyenangkan sehingga guru dan anak lebih saling mengerti, selain itu anak dapat lebih fokus dan tidak mudah jenuh dengan materi yang diberikan.

Untuk mengimplemantasikan hal tersebut maka penulis merancang buku ilustrasi interaktif yang bertujuan agar anak-anak di TK Al-Fauzi dapat belajar sopan santun dengan lebih menyenangkan karena menggunakan buku yang berisikan cerita ilustrasi yang dikemas dalam buku pop up. Media dalam proses pembelajaran dapat memengaruhi hasil yang dicapai oleh karena itu penggunaan media dalam pembelajaran sangat dianjuran untuk meningatkan atau memaksimalkan kualitas pembelajaran (Zaman dan Eliyawati, 2010: 1).

Berdasarkan riset yang penulis lakukan di TK Al-Fauzi, Penulis menemukan bahwa buku cerita mengenai akhlak sopan santun terbilang sedikit di TK tersebut sedangkan sopan santun merupakan materi penting yang harus diedukasikan kepada anakanak TK Al-Fauzi Medan, maka penulis memutuskan untuk mengangkat judul "Perancangan Buku Ilustrasi pop up dengan Tema Perilaku Sopan Santun Siswa dalam Kehidupan Sehari-hari untuk Tk Al-Fauzi Medan" sebagai judul karya Penelitian penulis agar dapat membantu para guru memberikan pembelajaran materi yang lebih menyenangkan.

Berdasarkan

rumusan

masalah di atas penulis menyampaikan tujuan penulisan akhir ini yaitu:

a. Mengetahui perancangan buku ilustrasi pop up dengan tema perilaku sopan santun dalam kehidupan sehari-hari.

b. Mengetahui hasil visualisasi perancangan buku ilustrasi pop up dengan tema perilaku sopan santun dalam ehidupan seharihari.

\section{METODE PENULISAN}

Penulisan Penelitian ini berdasarkan beberapa metode yang telah diperoleh dari pengumpulan data sehingga menjadi sebuah perancangan yang akhimya nyata sesuai dengan yang dikerjakan, yaitu :

Studi Pustaka merupakan teknik pengumpulan data dengan cara 
memelajari dan juga memahami berbagai buku dan sumber internet yang berhubungan dengan masalah yang ditulis agar diperoleh berbagai bahan dan data yang kemudian dijadikan landasan teori.

Penulis melakukan pengamatan dan penelitian yang dilakukan secara langsung di TK Al-Fauzi Medan yang penulis jadikan tempat untuk menyusun Penelitian ini untuk mendapatkan data.

Penulis melakukan wawancara dan diskusi dengan pihak-pihak yang berhubungan dengan objek penelitian yaitu kepala sekolah dan guru TK Al-Fauzi Medan agar memeroleh data yang dibutuhkan secara rinci.

\section{HASIL DAN PEMBAHASAN}

Dalam menciptakan suatu gagasan maupun ide, hal yang paling penting dilakukan adalah melakukan riset ke tempat sasaran untuk mengetahui pokok permasalahan yang sedang dihadapi agar gagasan tersebut tepat sasaran. Berdasarkan hsail riset yang telah penulis lakukan pada siswa TK Al-Fauzi Medan ditemukan beberapa anak yang merasa kurang tertarik untuk mendengarkan gurunya membacakan buku pokok. Setelah penulis mengetahui pokok permasalahan, tahap selanjutnya adalah tahap pencarian gagasan untuk siswa TK Al-Fauzi Medan dengan mengambil konsep buku ilustrasi pop up dengan tema sopan santun karena sopan satun merupakan salah satu materi pokok yang diberikan di TK AlFauzi Medan dengan tujuan agar para murid dapat belajar mengenai sopan santun dengan lebih menyenangkan dan memerhatikan guru.

Meskipun sudah memiliki beberapa buku ilustrasi, namun TK Al-Fauzi Medan hanya memiliki sedikit buku ilustrasi mengenai sopan santun itu sendiri, dikarenakan kebanyakan buku ilustrasi yang dimiliki adalah mengenai cerita Nabi. Oleh karena itu, dengan izin dari kepala sekolah, penulis merancang buku ilustrasi pop up dengan tema sopan santun sebagai sarana para guru memberikan materi kepada para murid.

Konsep yang ditawarkan dalam perancangan buku ilustrasi pop up dengan tema sopan santun ini adalah sebagai berikut :

a. Spesifikasi buku (Fisik). Ukuran buku ilustrasi pop up dengan tema sopan santun adalah 20 $\mathrm{cm} \times 20 \mathrm{~cm}$. Keseluruhan isi buku berjumlah 18 halaman. Sedangkan untuk jenis kertas, penulis menggunakan kertas TIK 260 gr pada isi dan pada cover menggunakan hard paper serta dijilid lux.

b. Sampul buku (cover). Pada sampul buku ilustrasi pop up dengan tema sopan santun, penulis membuat dengan menampilkan karakter utama dari buku ilustrasi tersebut. Dengan perpaduan warna yang cerah yang diharapkan dapat menarik perhatian para anak. Pada isi buku. Penulis membuat ilustrasi dengan style yang ramah dengan anak-anak dengan tujuan mudah 
untuk dikenali dan disukai oleh anak-anak. Penulis menggunakan metode cerita dalam penyampaian tentang apa saja sopan santun dalam kehidupan sehari- hari dikarenakan anak-anak lebih senang mendengarkan cerita dan dongeng dibanding penjelasan materi secara langsung. karakter di dalamnya bernama Haufanza yang dalam kamus nama anak berarti anak yang sopan, kemudian untuk membuatnya lebih ramah di telinga, maka penulis membuat Faza sebagai nama panggilannya. Diceritakan di dalamnya bahwa faza sedang belajar menerapkan sopan santun, mulai dari berpamitan dengan orang tua, menyapa teman, mendengarkan guru ketika menjelaskan, meminta izin ketika meminjam barang, berterimakasih ketika telah mendapat bantuan, menghormati orang yang lebih tua, meminta maaf ketika berbuat salah, dan membantu kedua orang tua.

Penataan layout yang digunakan dalam merancang buku ini yaitu berupa gaya modern eksperimental. Dengan kecenderungan gaya layout modern yang cenderung bersih dan sederhana, dikombinasikan gaya ilustrasi yang memiliki gaya

Pada tahap ini penulis merakit buku secara manual. Penulis mencetak hasil visual digital ke percetakan dan memotong bagian-bagiannya menggunakan gunting. Kemudian penulis membuat jembatan pola untuk pop up menggunakan sisa kertas cetakan yang tidak terpakai. Pada bagian membuang sampah anak-anak, sehingga menciptakan kombinasi layout modern bebas. Penggunaan layout yang tidak sepenuhnya modern bertujuan untuk mengantisipasi agar pembaca tidak bosan membaca buku

ini.

Setelah menentukan rancangan layout, maka penulis masuk pada tahap rancangan sketsa. Untuk perancangan buku ilustrasi pop up, penulis membuat sketsa-sketsa menggunakan pensil sebagai pengingat dan bentuk dasar sebelum masuk kepada rancangan dummy dan proses digitalisasi. Berikut merupakan sketsa yang telah penulis rancang.

Setelah menyelesaikan tahap pembuatan sketsa, maka tahap selanjutnya adalah masuk kedalam bentuk digital dengan proses digital drawing. Penulis dalam proses digital menggunakan software Adobe Photoshop CC 2019. Proses visualisasi buku ilustrasi pop up dengan tema sopan santun yang telah penulis buat terdiri dari tahap pembuatan sketsa, tahap pembuatan warna dasar, dan tahap pemberian shading.

penulis menggunakan plastik laminating yang sudah dipanaskan. Seluruh bagian dari perakitan buku, penulis merekatkannya menggunakan double tape agar menghindari kertas mengkerut bila menggunakan lem basah. Halaman halaman yang sudah selesai di susun disatukan juga menggunakan double tape. Setelah selesai bagian isi, penulis 
mulai membuat bagian hardcover dengan menggunakan hard paper, karton 1500 gr yang dilapisi stiker hasil visualisasi yang sudah dibuat.
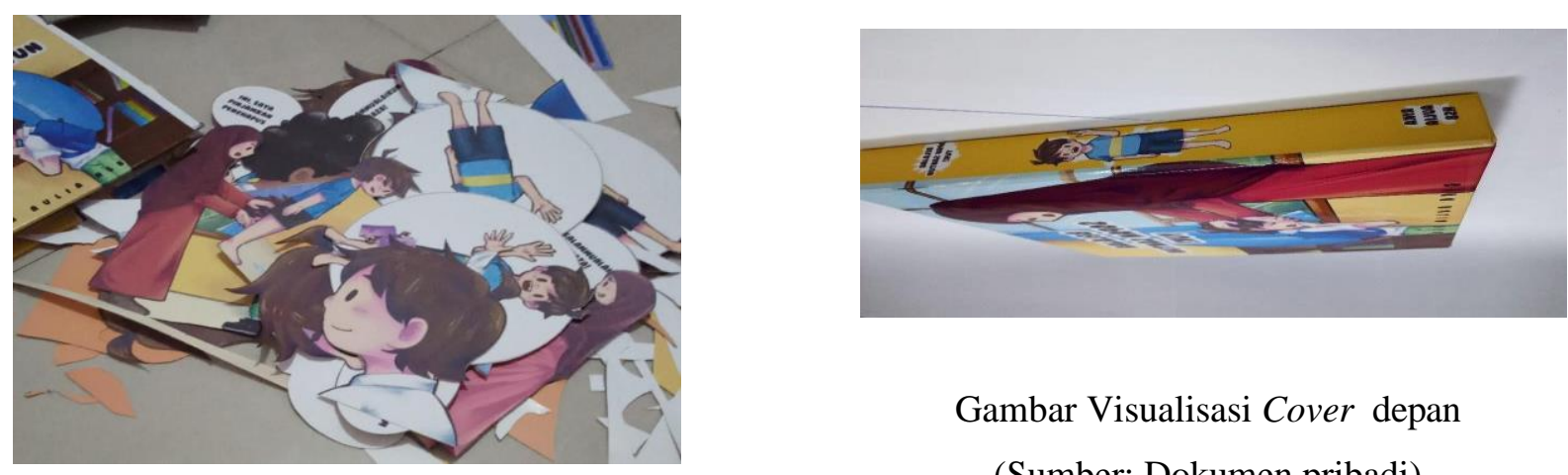

Gambar Visualisasi Cover depan

Gambar Proses Perakitan Buku

(Sumber: Dokumen pribadi) 
Publipreneur Polimedia: Jurnal Ilmiah Jurusan Penerbitan Politeknik Negeri Media Kreatif Vol. 5, No. 1, June 2017

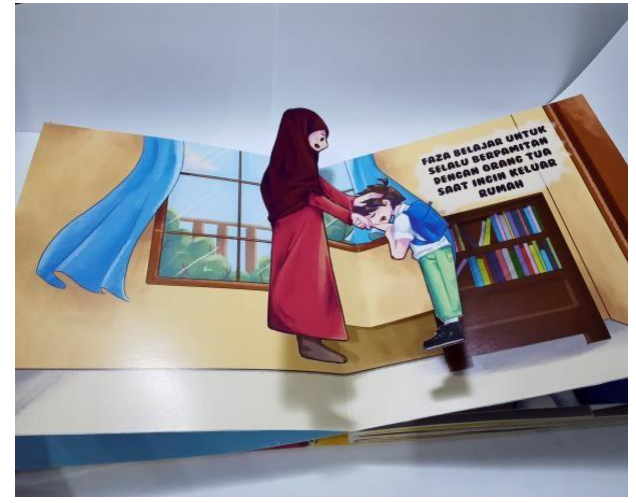

Gambar Visualisasi halaman 3-4

(Sumber: Dokumen pribadi)

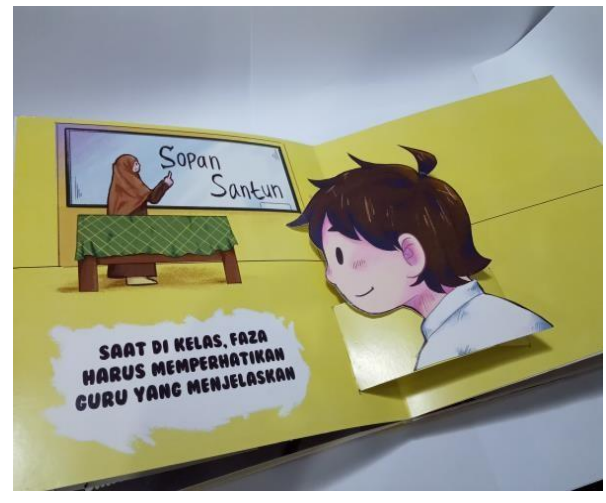

Gambar Visualisasi halaman 7-8

(Sumber: Dokumen pribadi)

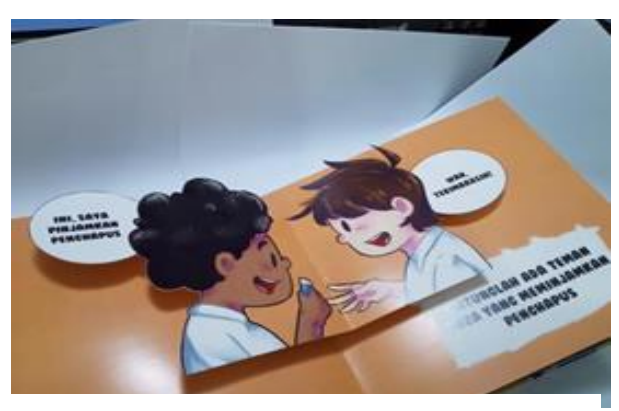

Gambar Visualisasi halaman 11-12

(Sumber: Dokumen pribadi)

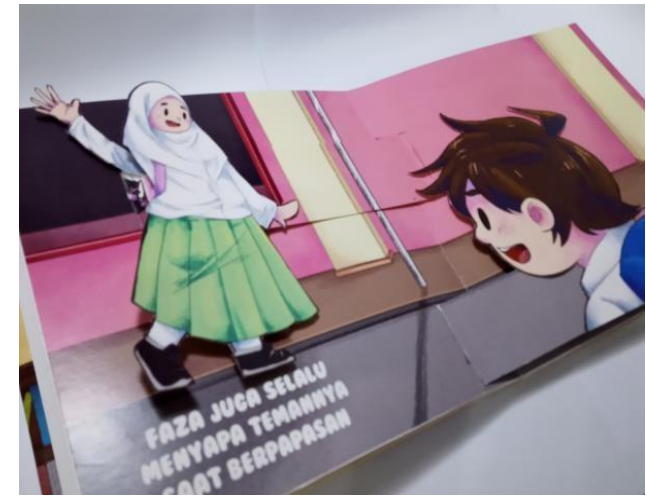

Gambar Visualisasi halaman 5-6

(Sumber: Dokumen pribadi)

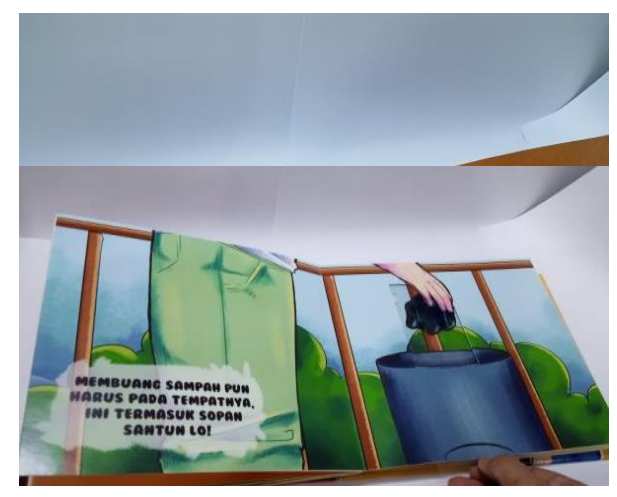

Gambar Visualisasi halaman 13-14

(Sumber: Dokumen pribadi) 


\section{KESIMPULAN}

Adapun kesimpulan dari penulis adalah sopan santun dapat dikenalkan pada pendidikan usia dini melalui perancangan buku ilustrasi pop up, siswa dapat memelajari sopan santun dengan pengalaman lebih menyenangkan melalui buku pop up. Pop up adalah media pembelajaran yang menarik bagi anak-anak karena lebih bervariatif. Pop up mempermudah siswa memahami materi yang akan disampaikan sehinga lebih efektif. Warna cerah dan gambar yang lucu dengan konsep pop up dapat lebih menarik perhatian siswa dalam belajar sopan santun. Membuat ilustrasi dengan style yang ramah dengan anak-anak dengan tujuan mudah untuk dikenali dan disukai oleh anak-anak. Penulis menggunakan metode cerita dalam penyampaian tentang apa saja sopan santun dalam kehidupan sehari- hari dikarenakan anak-anak lebih senang mendengarkan cerita dan dongeng dibanding penjelasan materi secara langsung. Diperlukan adanya kecenderungan gaya layout modern yang cenderung bersih dan sederhana, dikombinasikan gaya ilustrasi yang memiliki gaya anakanak, sehingga menciptakan kombinasi layout modern bebas. Penggunaan layout yang tidak sepenuhnya modern bertujuan untuk mengantisipasi agar pembaca tidak bosan membaca buku ini.

\section{DAFTAR PUSTAKA}

Andy. 2015. Menjadi Seorang Desainer.Yogyakarta

Anggraini, Lia S. \& Nathalia, K. 2016. Desain Komunikasi Visual Dasar-Dasar Panduan Untuk Pemula. Bandung: Nuansa Cendikia

Arifin dan Kusrianto. 2009. Sukses Menulis Buku Ajar dan Referensi, Jakarta: PT Gramedia Widiasarana Indonesia

Badru Zaman dan Cucu Eliyawati. 2010. Bahan Ajar Pendidikan Profesi

Guru,Media Pembelajaran Anak Usia Dini. Bandung: UPI <URL:

https://www.academia.edu/3 4912575/BAHAN_AJAR_PEND IDIKANPROFESI_GURU_PPG_ MEDIA_PEMBELAJARAN_AN AK_USIA DINI>

Dzuanda. 2009. Perancangan Buku Cerita Anak Pop Up, TokohTokoh Wayang Seri "Gatotkaca". Penelitian. Institut Teknologi Sepuluh November Surabaya.

Fariz. 2009. Living in harmony: jati diri, ketekunan, dan norma. Jakarta: PT Kompas Media Nusantara

Lestari, Suci. 2015. Perancangan Buku Mewarnai PAUD AlAzhari. Tugas Akhir. Desain Grafis

Lynch-Brown \& Tomlinson. 2008. "Essentials of Children Literature".<URL:http:/ /1001bu 
ku.org/mengenal-berbagaijenis-buku-bergambar/>

Nugraha, R.M. Pratama Adi. 2018. Perancangan Buku Edukasi 3D Pop Up dan Flashacard Mengenai Flora dan Fauna Indonesia Sebagai Media Pembelajaran Siswa Kelas 1 SD di Yayasan Pendidikan Citra Bangsa. Penelitian. Desain Grafis

Pratama, Febrian Eryanto Aji. 2011. Perancangan buku cerita bergambar "Pilt Monster Yang Tak Menyeramkan". Skripsi. Desain Komunikasi Visual

Permadani, Eky Dayanti Linda. 2016.

Peningkatan Perilaku Sopan Santun Anak Melalui Metode Sosiodrama pada Kelompok B TK Negeri Pembina Kecamatan Pringkuku Tahun Ajaran 2015/2016. Universitas Negeri Surakarta-FKIP Jurusan Pendidikan Anak Usia Dini <URL:https:// digilib.uns.ac.id/ dokumen/detail/52426/Pening katan-Perilaku-Sopan-SantunAnak-Melalui-Metode-

Sosiodrama-pada-Kelompok-B-

TK-Negeri-Pembina-

Kecamatan-Pringkuku-TahunAjaran-20152016>

Putra, Antonius, N., Lakoro, Rahmatsyam. 2012. Perancangan Buku Ilustrasi Musik Keroncong. Jurnal Teknik POMITS, Vol. 1, No. 1

Ramadhan, Faizal Arif. 2016. Perancangan Buku Ilustrasi “ Menjaga Kesehatan Mata Bersama Arva Dan Kawan-
Kawan" Untuk Anak Usia Kelas 3 - 5 SD. Skripsi. Fakultas Seni Rupa dan Desain. <URL:https://digilib.uns.ac.id/ dokumen/detail/57416/Peranc angan-Buku-Ilustrasi-Menjaga Kesehatan-Mata-Bersama-ArvaDan-Kawan-Kawan-UntukAnak-Usia-Kelas-3-5-SD>

Safitri, Ayu Widya. 2013. LKP : Pembuatan Layout Pada Program

Administrasi Pembukuan PT.

Setiawan, Leonard. 2016. Perancangan Buku Ilustrasi Pengenalan Nama BuahBuahan Dengan Sistem Isyarat Bahasa Indonesia (SIBI) Berbasis Karakter Untuk AnakAnak TKLB-B Karya Mulia Surabaya. Undergraduate thesis, Institut Bisnis dan Informatika Stikom Surabaya. $<$ URL:

http://sir.stikom.edu/id/eprin t/1738/4/BAB_II.pdff

Soedarso, Nick. 2014. Perancangan Buku Ilustrasi Mahapatih Gajah Mada. Humaniora. Vol. 5, No. 2, Oktober 2014, 561-570

Suwarno, Wiji. 2011. Perpustakaan \& buku: wacana penulisan \& penerbitan. Jogjakarta 